\title{
Ethical review of research into rare genetic disorders
}

M Parker, R Ashcroft, A O M Wilkie and A Kent

BMJ 2004;329;288-289

doi:10.1136/bmj.329.7460.288

Updated information and services can be found at:

http://bmj.com/cgi/content/full/329/7460/288

\section{These include:}

References

4 online articles that cite this article can be accessed at:

http://bmj.com/cgi/content/full/329/7460/288\#otherarticles

Rapid responses 4 rapid responses have been posted to this article, which you can access for free at:

http://bmj.com/cgi/content/full/329/7460/288\#responses

You can respond to this article at:

http://bmj.com/cgi/eletter-submit/329/7460/288

Email alerting Receive free email alerts when new articles cite this article - sign up in the service box at the top right corner of the article

Topic collections Articles on similar topics can be found in the following collections

- Other Ethics (1142 articles)

- Research and publication ethics (401 articles)

\section{Notes}




\title{
Ethical review of research into rare genetic disorders
}

\author{
M Parker, R Ashcroft R, A O M Wilkie, A Kent
}

Although some work on rare diseases is clearly clinical investigation and some clearly research, much activity falls uneasily between the two. Where should we draw the line and how can we ensure research gets appropriate ethical review?

\section{Editorial by Warlow}

Ethox Centre,

Department of

Public Health,

University of

Oxford, Oxford

OX3 7LF

M Parker

reader in medical

reader

Weatherall Institute

of Molecular

Medicine, John

Radcliffe Hospital,

Oxford, OX3 9DS

A O M Wilkie

Nuffield professor of

pathology

Medical Ethics Unit,

Imperial College

London, London

W6 8RP

$\mathrm{R}$ Ashcroft

Leverhulme senior

lecturer in medical

ethics

Genetic Interest

Group, London

N1 3QP

A Kent

director

Correspondence to:

M Parker

Michael.parker@

ethox.ox.ac.uk

BMJ 2004;329:288-9
Consider this case. A clinical geneticist telephoned a medically qualified researcher to discuss a patient with an unusual combination of clinical features. The patient presented a puzzle for diagnosis and for counselling about the genetic risk. Two months later, the clinician sent the researcher DNA from the patient, together with clinical photographs and copies of clinical letters. No mutation hotspots were found in relevant genes, and the sample was added to a "research panel." The clinician made further contact two years later, asking whether there were any positive results (the reply was negative) and providing some further clinical information.

Eventually, a further year and a half later and after tests of 13 genes had given negative results, the researcher contacted the clinician to say that a potentially pathogenic change in the DNA had been identified. The clinician was asked to obtain samples from the unaffected parents. The mutation was not present in either parent, establishing that the change had arisen de novo in the patient and was the cause of the clinical problem. Hence, three and a half years after the initial contact, the researcher had established unequivocally the correct diagnosis, mechanism of inheritance, and appropriate molecular test for the patient's condition.

Should this be considered research or clinical investigation?

\section{Problems of research classification}

Treating such cases as research creates important problems because of the process of ethical review. The first problem is that research ethics committees require consent to be closed - that is, samples must be used for a specific purpose and time which are clearly defined in advance. Small sample sizes in research into rare diseases mean that identifying disease-causing mutations is a type of informed fishing trip. The consent given is rarely capable of meeting the standards required.

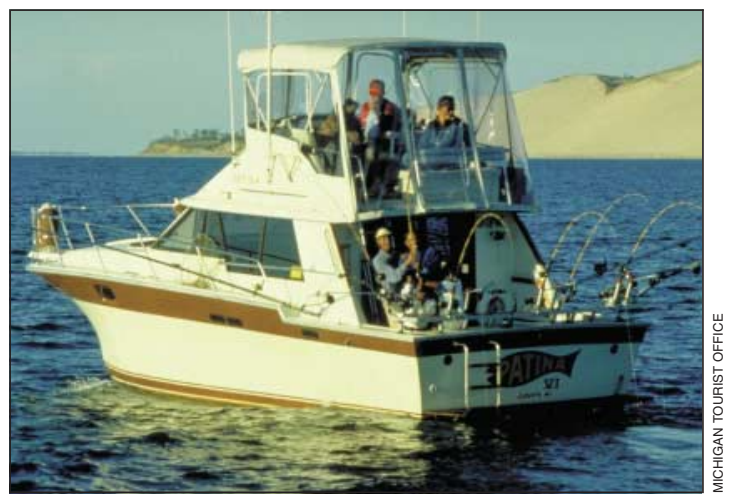

Genetic research can be like an "informed fishing trip"
Secondly, ethics committees do not always view the methods used to research rare conditions as meeting required methodological standards. ${ }^{1}$ Lastly, research into rare conditions is criticised for its standards of confidentiality. Such research often involves studying unique or near unique cases, making it impossible for participants to be anonymous.

Defining this work as clinical investigation sidesteps these problems but creates a problematic regulatory loophole. We believe that researchers should accept the need for ethics review and encourage the development of a more sympathetic regulatory structure. Agreement is needed about when clinical investigation turns into research and what is appropriate ethical review of research into rare inherited disorders.

\section{Research or clinical practice?}

One argument for classifying the above case as a clinical investigation is that the aim of the investigation is not to generate knowledge for its own sake but to provide a diagnosis and information about inheritance risk. Secondly, although some have alleged that such activities differ from clinical practice because they involve family members, it is good clinical practice in genetics to involve family members whenever possible. Thirdly, as clinical practice, it would continue to be subject to appropriate levels of regulation. It would be subject to the law (for example, on negligence) and to professional guidance ${ }^{2}$ and would not imply unacceptably low standards of protection. ${ }^{3}$

Although some aspects of the case resemble clinical practice, good reasons also exist for considering it as research. The characteristics that make such activities look insufficiently rigorous to ethic committees-that is, that they are fishing trips-also makes them look more like research than clinical practice. When a diagnosis is eventually reached, it is on the basis of a previously unknown mutation. It is not unusual for it take years to reach an understanding of the biological mechanisms, and the results are often published in peer reviewed journals. In addition, the involvement of family members can evolve into something that no one would dispute was research. The most obvious point at which this happens is when case finding moves from a single family to a search for additional affected individuals and families. Finally, classifying investigations as research may provide access to funding that would otherwise be unavailable.

\section{When does clinical practice become research?}

An unambiguous distinction between clinical practice and research is impossible. Some differences are discernable, however. Once an investigation moves from a single family to the solicitation of affected but 
unrelated individuals it has undeniably become research. At the other end of the spectrum, when mutations are searched for to find a diagnosis in an individual, this looks like clinical practice, as does checking against samples from blood relatives to see whether the patient has a de novo mutation.

Between these two markers things become less clear, and it is unrealistic to expect to find an unambiguous dividing line. Given this, a pragmatic solution is required. We suggest that investigations that go beyond the identification of mutations in unsolicited single families (and confirmation or exclusion in blood relatives) should be considered as research and subject to ethical review-in other words, studies in which the researcher actively recruits new cases.

\section{Improving ethical review}

Developing tests and therapies for rare genetic disorders depends on a more sympathetic approach to the review of such research. What should be the appropriate process of research ethics review? The best way to consider this is in terms of the three problems identified earlier: consent, anonymity, and methodology.

\section{Open ended versus closed consent}

Except in exceptional circumstances, research participants should be included in studies only if they have given their valid consent. What ought to count as valid consent in research into rare conditions?

To be valid, consent must be voluntary, informed, and competently given. Research ethic committees have tended to interpret the requirement for informed consent to imply that such consent must be specific and closed. Consent is informed only if participants know in detail what is going to happen to them, what is going to happen to any sample taken from them, and when the research will be completed. In research into rare conditions it is not always possible to provide the participant with a detailed account of this kind. This need not imply, however, that informed consent is not possible. Given adequate support, research participants are able to understand the nature of rare disease research sufficiently well to enable them to give valid consent. The true test of validity, we suggest, is whether the participants have sufficient understanding of the research and of their part in it to enable them to make a reasoned and balanced assessment about whether to participate.

\section{Anonymity}

High standards of confidentiality and anonymity are important in research. When asked, patients and research participants consistently place high value on confidentiality. They also place high value on good quality research and the achievement of results. ${ }^{4}$ In rare disorders these goals need to be carefully balanced against the realities of such research. The appropriate balance between anonymity and research efficacy should be judged according to a combination of empirical evidence about what participants consider acceptable practice and recognition of the need to protect family members who do not want participate in research.

\section{Rigorous methodology}

It is unreasonable for ethics committees to apply inappropriate standards of research methodology to research on rare diseases. Research on small sample

\section{Summary points}

Differentiating between clinical practice and research can be difficult in genetics

It is impossible for many genetic studies to meet current standards for ethical approval

Studies going beyond the immediate family should be defined as research

Ethics committees need to take into account the special problems of consent, anonymity, and method in research into rare diseases

sizes requires different methods from those used in large trials. The review of research into rare inherited disorders should ensure that the research methods are appropriate to the task.

\section{Conclusions}

Research into rare inherited disorders encounters difficulties in ethical review. This can delay the approval of such research and threaten its viability. If the result of this is to prevent such research occurring, this consequence is itself unethical. The best way to overcome such difficulties is by adopting a pragmatic distinction between clinical practice and research and developing a more sympathetic review process. To achieve this we need to carry out empirical research into the attitudes of families with inherited disorders about key ethical values and ensure that ethics committees give this due weight when considering research proposals. We also need to educate committee members, research funders, and journal editors about the appropriate methods of research on rare conditions.

We thank the patient groups, researchers, clinicians, research funders, ethicists, and lawyers who participated in the three workshops on these issues held in Oxford and London. These workshops were funded by the Wellcome Trust and the Oxford Genetics Knowledge Park. We also thank Maggie Ponder, John Gillott, and Melissa Winter.

Funding: The Oxford Genetics Knowledge Park is funded jointly by the UK Department of Health and the Department of Trade and Industry. AOMW's research is funded principally by the Wellcome Trust.

Contributors and sources: MP provides ethics support to the Regional Clinical Genetics Unit in Oxford and co-organises the UK Genethics Club (www.genethicsclub.org). RA teaches ethical issues in medical research and genetics to medical students and clinicians and has served on a number of research ethics committees. AOMW is a clinical geneticist working both clinically and as a researcher with patients and families with rare inherited disorders. AK is director of the Genetic Interest Group, a UK alliance of patient and user groups supporting all those affected by genetic disorders. One aspect of its mission is to help create a climate within which high quality research is encouraged. MP is guarantor.

Competing interests: None declared.

Department of Health. Research governance framework for health and social care. London: DoH, 2003:para 1.9. www.dh.govuk/assetRoot/04/01/47/ 57/04014757.pdf (accessed 5 Apr 2004)

2 General Medical Council. Confidentiality: protecting and providing information. London: GMC, 2000

3 Department of Health. Good practice in consent implementation guide: consent to examination or treatment. www.dh.gov.uk/assetRoot/04/01/90/61/ 04019061.pdf (accessed 13 Jul 2004).

4 Genetic Interest Group. Minutes for research approval and rare genetic disorders workshop, 30 April 2003. www.gig.org.uk/docs/researchapproval2.pdf (accessed 13 Jul 2004).

(Accepted 13 July 2004) 